\title{
CONSTÂNCIA \\ LIMA DUARTE
}

\section{ENTREVISTA $^{1}$}

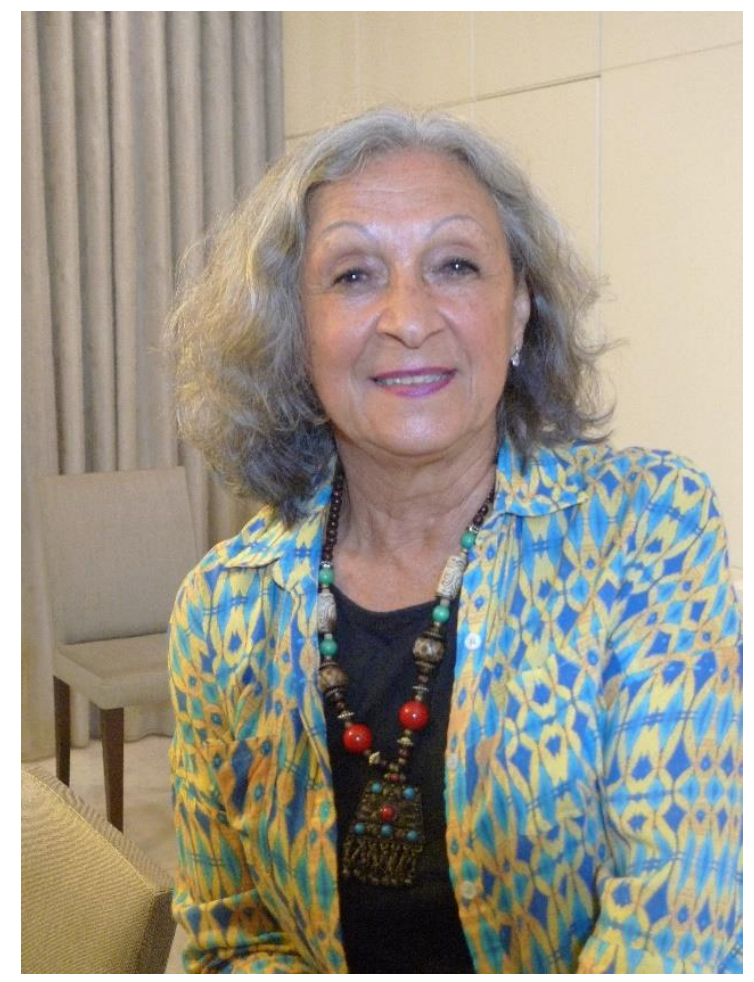

Constância Lima Duarte é professora aposentada da Faculdade de Letras da Universidade Federal de Minas Gerais-UFMG. Doutora em Literatura Brasileira pela Universidade de São Paulo-USP, realizou várias pesquisas de pós-doutorado na Universidade Federal de Santa Catarina-UFSC e na Universidade Federal do Rio de Janeiro-UFRJ. Atualmente, enquanto Pesquisadora do CNPq, desenvolve atividades voluntárias, ora ministrando cursos e palestras - em nível nacional e internacional -, ora pesquisando e orientando dissertações, teses e estágios pós-doutorais. Desde 2011 coordena um Grupo de Pesquisa na UFMG

- Letras de Minas/Mulheres em Letras - que reúne professoras de diversas instituições do Estado, dedicado a estudar a obra de escritoras brasileiras e a organizar eventos visando sua divulgação. É também pesquisadora do Núcleo de Estudos

\footnotetext{
${ }^{1}$ Entrevista concedida a Iara Barroca em junho de 2020.
} 
Interdisciplinares da Alteridade (NEIA) e do Centro de Estudos Literários da UFMG. Autora de inúmeros livros sobre teoria e crítica acerca da escrita produzida por mulheres, destaco aqui seu livro publicado em 2016: Imprensa feminina e feminista do Brasil-Século XIX: dicionário ilustrado, fruto de intensa e dedicada pesquisa sobre a história das mulheres e do movimento feminista no Brasil. Este dicionário apresenta uma extensa cartografia, que vai de norte a sul do país, por meio da qual a autora expõe, com exímia originalidade e competência, o eficiente papel de mapa e guia norteador de novas pesquisas, contribuindo, assim, para o preenchimento de lacunas acerca da história da mulher brasileira, especialmente no que diz respeito à busca pelos direitos, à possibilidade de construção de identidades femininas e à visibilidade subjugada por que buscam, há séculos, as mulheres.

Prezada Professora Dra. Constância, é um prazer imenso e uma alegria imensurável poder estar diante de você para aprender e compreender tantas particularidades inerentes ao mundo - ou ao submundo - no qual as mulheres se inserem. Agradeço, profundamente, sua disposição e pronta disponibilidade em me receber, para falarmos de uma temática tão forte e essencial para o mundo. Muito obrigada!

IARA BARROCA: O foco da sua obra, no caso a literatura de autoria feminina, é algo pouco explorado, mesmo no meio acadêmico. Isso reflete de alguma forma a condição da mulher dentro da sociedade? Mesmo a sociedade ocidental que apregoa uma suspeitável igualdade de "gêneros"?

CONSTÂNCIA LIMA DUARTE: Não, não é bem assim. Os estudos envolvendo a mulher, a literatura e as artes, em geral, estão hoje na ordem do dia nas universidades brasileiras e em muitas estrangeiras. E poderia completar: ainda bem, já era hora disso acontecer. Até uns vinte anos atrás - eu concordo - o estudo sobre a mulher escritora ou a sua representação na literatura não era nem considerado um objeto legítimo de pesquisa. A consolidação de trabalhos dessa natureza é consequência da iniciativa de grupos de pesquisadoras ao desenvolver estudos e apresentar os resultados de suas pesquisas nos congressos da área.

E a tendência de expansão dessa linha de trabalho é inegável, basta observar o número crescente de livros publicados, dissertações e teses que a todo momento são defendidas. Mas concordo que é questionável a igualdade de "gêneros" apregoada pela sociedade ocidental. Apesar de tantas conquistas nos inúmeros campos de conhecimento e da vida social, ainda Jangada | nr. 15, jan/jun, 2020 | ISSN 2317-4722 
persistem nichos patriarcais de resistência. Basta lembrar o salário inferior, a presença absurdamente desigual de mulheres em assembleias e em cargos de direção, além da ancestral violência que continua sendo praticada com a mesma covardia e abuso da força física. Ainda falta muito, é verdade. Mas um dia chegamos lá.

IARA: Você acredita que existe uma literatura feminina, ou não há uma distinção relevante?

CONSTÂNCIA: Esta é uma questão polêmica e que sempre é apresentada quando se fala em literatura de autoria feminina. Eu penso que sim, que pode existir uma especificidade no texto escrito por uma mulher. Basta que ela deixe em seu texto as marcas de sua vivência, ou de sua experiência, se preferir. Tal questão só passou a ser colocada quando as mulheres entraram no mundo das letras. Antes, quando só os homens escreviam, seus escritos se confundiam com a própria ideia de Literatura. Já a diversidade contemporânea permite, e até instiga, que grupos tradicionalmente excluídos do poder cultural reivindiquem uma marca identitária especifica, para o que escrevem.

IARA: Poderia contar um pouco sobre a sua trajetória de pesquisadora da imprensa vinculada à área de Letras? Como surgiu seu interesse pelos periódicos?

CONSTÂNCIA: Como professora de Literatura Brasileira, sempre me incomodou a ausência de nomes de mulheres nos livros de história literária, nas antologias e manuais de literatura. $\mathrm{E}$ foi procurando pelas primeiras escritoras que me deparei com os periódicos "femininos", onde elas publicavam seus poemas e textos em prosa. Na época, achei interessante constatar que foram os jornais, e não os livros, os primeiros veículos utilizados pelas escritoras, e que eles se tornaram valiosos espaços de divulgação e de resistência. Outra constatação foi observar que literatura, imprensa e consciência feminista surgiram praticamente ao mesmo tempo no Brasil, nas primeiras décadas do século XIX. Quando as primeiras mulheres tiveram acesso ao letramento, imediatamente se apoderaram da leitura, que por sua vez as levou à escrita e à crítica. E independente de serem poetisas, ficcionistas, jornalistas ou professoras, a leitura lhes deu consciência do estatuto de exceção que ocupavam no universo de mulheres analfabetas, da condição subalterna a que o sexo estava submetido, e propiciou o surgimento de escritos reflexivos e engajados, tal a denúncia e o tom reivindicatório que muitos deles ainda hoje contêm. 
IARA: O Jornal das Senhoras não foi o primeiro jornal escrito por mulheres. Por que durante tanto tempo ele foi considerado como sendo o primeiro?

CONSTÂNCIA: Creio que o Jornal das Senhoras foi considerado o primeiro do país dirigido por uma mulher principalmente pelo fato de ter sido publicado no Rio de Janeiro, em plena Corte, e tratar de questões de interesse das mulheres. Em 1833 já havia circulado em Porto Alegre dois periódicos dirigidos por Maria Josefa Barreto (1786?-1837), intitulados Belona Irada contra os Sectários de Momo e Idade d'Ouro, mas que eram políticos e se posicionavam francamente a favor do Partido Conservador. E outros, como A Mineira no Rio de Janeiro (1833), escrito do ponto de vista de uma mulher que não se identifica, também fazia apelos enfáticos “às Brasileiras” para que se envolvessem com a política. Não deixa de ser interessante observar que os primeiros periódicos femininos não trataram de questões específicas do gênero. O clima conturbado que dominava o país durante o vazio de poder existente entre o reinado de Pedro I e Pedro II, levava o "segundo sexo" - quisessem ou não os homens - a tomar partido e eleger a política como tema prioritário.

IARA: O que, de fato, caracteriza a luta feminista?

CONSTÂNCIA: A história das conquistas feministas pode ser compreendida a partir das especificidades das reinvindicações. Cito algumas, a título de exemplo: a primeira luta abraçada pelas feministas, ainda nas primeiras décadas do século XIX, foi o direito das mulheres de serem consideradas dotadas de inteligência e, portanto, poderem ser alfabetizadas... Entre 1830 e 1870 tivemos inúmeros periódicos, como Espelho das Brasileiras (1831), A Mineira no Rio de Janeiro (1833), Jornal das Senhoras (1852-1855), O Belo Sexo (1862) e O Sexo Feminino (1873-1889), dedicados principalmente a reivindicar o direito das meninas à educação formal. Dentre as escritoras do período, lembro o nome de Nísia Floresta que publicou diversos livros, entre eles Direitos das mulheres e injustiça dos homens, de 1832, e Opúsculo Humanitário, de 1853, que denunciavam a opressão social exercida sobre as mulheres.

Vencida esta etapa, nas últimas décadas do século XIX e nas primeiras do XX, as feministas passaram a pleitear o acesso à educação secundária e à universitária, permitindo o surgimento das primeiras médicas e advogadas do país. Também teve início nesta época a luta pelo trabalho remunerado, o direito ao voto e ao divórcio. O primeiro estado brasileiro a permitir o voto Jangada | nr. 15, jan/jun, 2020 | ISSN 2317-4722 


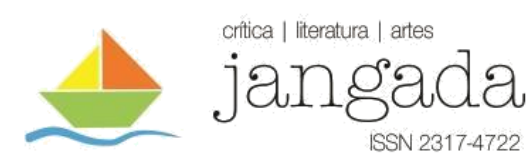

feminino foi o Rio Grande do Norte, que, em 1827, elegeu nossa primeira prefeita - Alzira Soriano, em Lages. Em âmbito nacional, o voto só foi aprovado em 1932 e concretizado em 1933, na eleição para a Assembleia Constituinte.

Após estas conquistas, surgiram outras bandeiras como a liberação sexual, na década de 1960, impulsionada pelo aumento dos contraceptivos, e a luta pela igualdade salarial no trabalho e pelos direitos reprodutivos, iniciadas nos anos 1970, entre outras. Mas não tem sido fácil. A prova disso é que ainda hoje algumas antigas reivindicações, como o fim da diferença salarial entre homens e mulheres, e o fim da violência de gênero, permanecem atuais e se apresentam como bandeiras a serem conquistadas.

IARA: Qual a relação entre feminismo e literatura no atual contexto político de reivindicação?

CONSTÂNCIA: Esta é uma questão delicada, até porque muitas escritoras parecem querer escamotear a experiência de gênero em suas obras... A crítica literária e a mídia têm uma parcela de culpa nisso, eu penso. Quando surgiram as primeiras escritoras, em meados do século XIX, suas obras foram criticadas justamente por tratarem de questões relacionadas à condição feminina; ou seja, por falarem do ponto de vista da mulher. Por isso, nessa época, muitas escritoras usaram pseudônimos (e não só no Brasil), visando preservar sua imagem e proteger seu círculo mais íntimo da pressão social, advinda da exposição pública. Havia uma "censura no ar", uma oposição implícita contra a mulher que escrevesse. O anonimato também permitiu às mulheres escamotear o conflito que devia ser motivo de angústia para muitas: proteger-se e ter vida privada, ou assinar uma obra e expor-se pela publicação de suas ideias. Entre o ideal feminino e a imagem de artista havia, nesses tempos, uma incompatibilidade quase inconciliável. Virgínia Woolf sugere, inclusive, que muitos daqueles "Anônimos" que escreveram tantos poemas, romances e novelas antigamente devem ter sido, na verdade, “Anônimas", no feminino, o que bem pode ser possível.

Mas, apesar do preconceito, muitas não se intimidaram e assinaram suas obras, como Carmen Dolores (1852-1910), Júlia Lopes de Almeida (1862-1934) e Gilka Machado (18931980), que publicaram livros denunciando a precariedade da condição feminina em seu tempo.

A partir de meados da década de 1950, principalmente, com o aumento da escolaridade e das conquistas sociais, o número de escritoras aumenta consideravelmente e suas obras se impõem no cenário literário, a ponto de a crítica não poder mais ignorá-las. Rachel de Queiroz, Jangada | nr. 15, jan/jun, 2020 | ISSN 2317-4722 


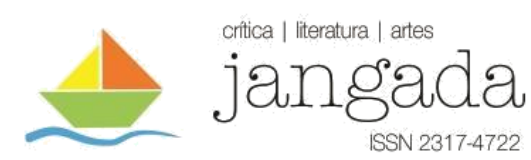

Clarice Lispector, Lygia Fagundes Telles, Hilda Hilst, por exemplo, surgiram nesta época, e vão mudar definitivamente o perfil que a literatura nacional tinha até então.

Em 1970, a partir do impulso provocado pelo movimento feminista, dezenas de pesquisadoras(es) se lançam ao trabalho de resgatar antigas escritoras, fazer a revisão do cânone e da crítica literária, com o propósito de tornar conhecida a contribuição feminina. Foi dessa forma que dezenas de novos/antigos nomes, e novas/antigas obras, ressurgiram do esquecimento, e foi possível conhecer a tradição literária das mulheres em nosso país.

IARA: Qual das três vertentes principais do feminismo - individualista, liberal, radical melhor justifica essa luta, considerando o posicionamento das escritoras no passado?

CONSTÂNCIA: Creio que não é possível restringir o posicionamento das antigas escritoras a uma só vertente, até porque elas eram muitas e construíram obras diversas. Algumas se identificaram com a vertente individualista, como Júlia Lopes de Almeida (1862-1934), autora de mais de 40 títulos, dentre romances, contos, novelas e teatro. Outras se afinaram com o liberalismo, como Maria Lacerda de Moura (1887-1945), anarquista, fundadora da "Liga para a Emancipação Intelectual da Mulher", e autora de diversos livros censurados, como A mulher é uma degenerada? (1924), tal a polêmica que provocou. E tivemos ainda as que não fizeram concessões, como Ercília Nogueira Cobra (1891-?), dona de um estilo agressivo, corajoso e irônico, e autora de apenas dois livros que foram suficientes para torná-la conhecida: o ensaio - Virgindade anti-higiênica, de 1924, e a ficção, Virgindade inútil, novela de uma revoltada, de 1926. Em ambos, ela defende o amor livre e denuncia a hipocrisia religiosa que vitimava as mulheres. O sucesso dos livros pode ser calculado pelas diversas reedições e por terem sido alvo da ação da polícia, que chegou a invadir livrarias para recolhê-los.

IARA: A que atribui a falta de atenção ao periodismo por parte da historiografia da literatura brasileira?

CONSTÂNCIA: Creio que são muitos os fatores envolvidos, como, por exemplo, a desvalorização do veículo e o desconhecimento de seu papel na construção cultural da sociedade. Mas o principal fator deve ser nosso tradicional desprezo pela história e por tudo que envolve o passado. Falta-nos a cultura da preservação e, por isso, sobra o memoricídio, isto é, o sistemático apagamento da memória cultural. No caso das mulheres isso ocorre (ou ocorreu) Jangada | nr. 15, jan/jun, 2020 | ISSN 2317-4722 
com muito mais virulência, pois não só seus textos literários foram ignorados, como também sua produção jornalística, sua história de luta e resistência. Os nomes das pioneiras só começaram a aparecer após o trabalho de resgate feito por um grupo de pesquisadoras, nas duas últimas décadas. E se as escritoras estiveram invisíveis na história literária dos séculos XVIII e XIX, isso se deve ao corporativismo masculino, pois durante muito tempo só os homens ocuparam os espaços de poder. E entre um autor e uma autora, os editores, jornalistas, críticos e pesquisadores, sempre preferiram divulgar o escritor. Enfim, foram muitos vícios da sociedade patriarcal que as mulheres tiveram que enfrentar quando deixaram de ser apenas leitoras e se tornaram também escritoras.

IARA: Que critérios utilizou em seu trabalho de elaboração do dicionário ilustrado para estabelecer o corpus dos periódicos considerados femininos e feministas?

CONSTÂNCIA: Após um amplo levantamento dos periódicos que tinham como público alvo as mulheres, realizado em acervos e arquivos de bibliotecas, em livros e, posteriormente, em sites da internet, a segunda etapa consistiu em observar não mais a quem se dirigia a publicação, mas como se dirigia às leitoras. E logo ficou evidente duas tomadas de posição bem distintas: uma, que endossava o status quo, ou seja, que reforçava os tradicionais papéis de esposa carinhosa, boa dona de casa e filha obediente, além da imagem de mulher vaidosa e preocupada com a moda. E outra, que denunciava a opressão e exigia a ampliação de direitos civis e políticos. Por uma questão didática, chamei os primeiros de "femininos" e os demais de "feministas". Mas é importante ressaltar que tanto mulheres como homens participaram das duas categorias de periódicos, e, muitas vezes, encontramos artigos incrivelmente revolucionários ao lado de outros conservadores, no mesmo periódico. Também é preciso destacar que ambas as modalidades tiveram participação decisiva na formação intelectual da mulher, e na construção cultural e discursiva de sua identidade.

Na organização do dicionário, os periódicos foram apresentados por ordem cronológica de publicação, e cada verbete contém, sempre que possível, o subtítulo do jornal ou revista, o nome do editor ou da editora, a cidade de origem, a tipografia, as datas do primeiro e último números, a proposta editorial, o formato gráfico e a relação dos principais colaboradores e colaboradoras. Informo ainda quais foram os exemplares examinados, onde se encontram, e referências bibliográficas. A extensão dos verbetes varia principalmente em função de se ter tido ou não acesso aos originais e a fontes de informação. Enquanto alguns já possuem um Jangada | nr. 15, jan/jun, 2020 | ISSN 2317-4722 
volume razoável de estudos, outros podem ser conhecidos apenas pelo registro que receberam de outros pesquisadores.

IARA: Além do conteúdo cultural, o levantamento das publicações periódicas desvendou uma participação das mulheres jornalistas no campo político. O que o estudo da imprensa permite conhecer a respeito da perspectiva política nos escritos femininos?

CONSTÂNCIA: O estudo da imprensa nos permite saber que existiram mulheres no século XIX antenadas às questões políticas de seu tempo, e que usaram a imprensa para se manifestar e se posicionar politicamente, a favor ou contra a Monarquia, a Revolução Farroupilha, a Constituinte, a Abolição ou a República. Dentre muitos títulos, lembro: Belona Irada contra os Sectários de Momo (1833-1834) e Idade d'Ouro (1833), ambos de Porto Alegre, dirigidos pela escritora Maria Josefa Barreto; República das Moças (1879), O Abolicionista do Amazonas (1884) e Ave Libertas (1885), cujos títulos já dizem sobre o posicionamento das editoras. Outros se empenharam em conscientizar as leitoras de seus direitos à educação, à propriedade, ao voto e ao trabalho, e contestaram o mandonismo patriarcal e o comportamento domesticado das mulheres, como O Sexo Feminino (1873-1889), A Mulher (1881-1883), A Mensageira (18971900) e O Escrínio (1898-1910), etc etc.

IARA: O mapeamento do periodismo feminino no Brasil indicou que a existência de uma rede de apoio e cooperação entre as publicações foi fundamental para garantir espaço às escritoras jornalistas. A rede de contatos e intercâmbios se limitava ao país ou possuía caráter transnacional?

CONSTÂNCIA: A partir de 1870, os órgãos feministas se multiplicam por todo o país, contribuindo para minimizar o isolamento das mulheres, divulgar as conquistas e realizar uma espécie de intercâmbio intelectual entre eles, e entre elas, as redatoras. Ao se articularem, as jornalistas estabeleceram uma espécie de rede de apoio, que divulgava os novos jornais e transcreviam notícias sobre os avanços da situação feminina, no Brasil e nos outros países. Dou um exemplo emblemático: em 1880, duas jovens pernambucanas - Maria Augusta Generosa Estrela e Josefa Águeda Felisbella Mercedes - foram cursar medicina no New York Medical College and Hospital for Women, e lá criaram o periódico A Mulher (1881-1883), que circulou 
em Nova York e em Recife, e trazia textos em inglês e espanhol, além de português, dedicados a incentivar as jovens a fazerem o curso superior, principalmente.

IARA: Quanto à presença da literatura no periodismo do século XIX, notou diferença entre as publicações da corte e as das demais províncias?

CONSTÂNCIA: Sinceramente, não muita diferença, o que também foi motivo de surpresa. Em pequenas cidades do interior do Ceará, da Bahia, ou de Minas Gerais, e mesmo em pequenas capitais, como Manaus, Fortaleza e Natal, circularam periódicos que estavam em sintonia com a estética romântica dominante, e também com as novas ideias sobre os avanços alcançados pelas mulheres naquele momento histórico.

IARA: "Uma das razões para a criação dos periódicos de mulheres no século XIX partiu da necessidade de conquistarem direitos. Em primeiro lugar, o direito à educação; em segundo, o direito à profissão e, bem mais tarde, o direito ao voto. Quando falamos dos periódicos do século XIX, há que se destacar, pois, essas grandes linhas de luta. O direito à educação era, primordialmente, para o casamento, para melhor educar os filhos, mas deveria incluir também o direito de frequentar escolas, daí decorrendo o direito à profissão.” Com base nestas palavras de Zahidé Lupinacci Muzart, na quarta capa de seu dicionário ilustrado sobre a Imprensa feminina e feminista no Brasil, como você vê a questão de a autoria feminina ter se manifestado nos periódicos do século XIX?

CONSTÂNCIA: Como os jornais se constituíram em espaço privilegiado para a divulgação da literatura, e a maioria das escritoras publicaram antes em suas páginas, é possível encontrar aí o nascedouro de muitas vocações literárias. Mas lembro um detalhe importante: assinar uma publicação naquele tempo representava um ato de coragem, pois significava tornar públicas suas ideias... E nem toda mulher tinha coragem para tanto. Mas, como disse, muitas não se intimidaram, assinaram suas obras e publicaram livros denunciando a precariedade da condição feminina em seu tempo.

IARA: Em sua opinião, que perspectivas futuras a investigação em fontes primárias lança para os estudos literários? 
CONSTÂNCIA: Penso que os estudos literários têm muito a ganhar com a pesquisa em fontes primárias, porque estão lá - encantados nos acervos de antigas bibliotecas - um manancial literário talvez ainda desconhecido da historiografia. Acredito que, uma vez descobertos, muitos periódicos devem propiciar novas reflexões acerca da tradição literária das mulheres, da profissionalização das primeiras jornalistas, do papel das revistas e jornais na ampliação do público leitor e na conscientização feminina. Também devem revelar os gêneros literários em voga e os avanços obtidos pelo segmento feminino na política educacional, entre outros aspectos.

IARA: O que mudou na construção cultural e discursiva da identidade da mulher pelas imprensas feminista e feminina do século XIX até hoje?

CONSTÂNCIA: Penso que finalmente as diferenças identitárias existentes entre as mulheres estão sendo consideradas. E as lésbicas, as negras e as trans, cada uma está sendo vista e apresentada em sua especificidade. Porque não se pode mais falar em "mulher", mas em mulheres. Daí a urgência do fortalecimento do feminismo negro, que se diferencia por defender as necessidades e demandas relativas à mulher negra. Historicamente, o movimento feminista sempre privilegiou as pautas de mulheres brancas, heterossexuais, da classe média e alta, e universalizou a categoria mulher como se todas sofressem o mesmo tipo de opressão. $\mathrm{O}$ que não é verdade. No passado, enquanto as brancas estavam confinadas no espaço doméstico; as negras, por uma contingência da condição de escravizadas ou de libertas, sempre estiveram no espaço público lutando pela sobrevivência. A única verdade é que toda mulher - independente da etnia, sexualidade e classe social - sofre com o machismo, com a misoginia e com o falocentrismo - os pilares do patriarcado. 